\title{
MONTESQUIEU E A IDEIA DE PARLAMENTO NO ANTIGO REGIME
}

\author{
Ana Paula Cianciosa dos Reis \\ e-mail ana.paula_art@hotmail.com
}

UNESP

Resumo: Para se estudar no pensamento de Montesquieu a ideia de parlamento como sendo um dos aspectos relevantes de suas interpretações, deve-se considerar a vida, a obra e a sua instituição na França. Nosso objetivo com esta análise é procurar traçar outros percursos a partir do período que Montesquieu exerceu sua função de magistrado no Parlamento de Bordeaux entre 1714 a 1726 sendo primeiro conselheiro e depois "Président à mortier". A análise deste momento da vida de Montesquieu pressupõe os anos de formação, a herança do cargo judiciário e as reflexões sobre o parlamento e governo monárquico. Em vista disto, nossa pesquisa visa também explicitar a instituição do parlamento na França que foi estabelecido primeiramente em Paris no século XIII como prolongamento do Conselho do Rei: $\mathrm{O}$ século $\mathrm{XV}$ foi à época onde se multiplicaram as criações deles em várias províncias dentre elas em Bordeaux em 1462. No quadro institucional do Antigo Regime, os parlamentos das províncias tinham múltiplas funções. A autoridade constituída nestes parlamentos era a "corte soberana" de um sistema institucional de "justiça delegada" e é exercida em nome do rei. E os parlamentos eram considerados de fato representantes da justiça real e do poder político e civil.[ Os parlamentares exerciam seu poder que consistia em aceitar ou refutar oficialmente as leis e os decretos que emanavam do Conselho do Rei, e suas ações passaram a ser diretamente simbolizadas numa oposição política. Montesquieu analisa estes conflitos e escreverá nas suas criticas e nas suas reflexões diversas ideias que nos mostram que o parlamento como "corpo intermediário" e subordinado a monarquia deve ser considerado como oposição indispensável e ao mesmo tempo caracteriza-se uma relação de interdependência entre este 'corpo' e o rei. Quando escreve as Cartas Persas e publica em 1721 está exercendo suas funções no Parlamento de Bordeaux, e a interpretação de algumas cartas será pertinente ao tema que propomos examinar. Estas são as considerações que desejamos com este estudo.

Palavras-chave: Parlamento, Monarquia e "Conselho do Rei"

Na França, durante o Antigo Regime monárquico, vê-se instituir no século XIII o Parlamento de Paris e seu papel principal era exercer suas funções como forma de prolongamento do "Conselho do Rei". E somente no século XV que ocorre em diversas províncias, dentre elas a de Bordeaux em 1462, as instituições dos Parlamentos. O 
período que circunscrevemos trata principalmente do início do século XVIII no qual Montesquieu pensa os parlamentos no plural, nas diferenças regionais e que não deviam estar simplesmente ligados ao Parlamento de Paris e submeterem-se aos seus únicos interesses. Reconhecia a importância que estas "cortes soberanas" representavam na monarquia francesa, e escreve numa outra obra Mes Pensées, 589: “Ainda que os parlamentos da França não tenham grande autoridade, eles não deixam de fazer o bem. Nem o ministério e nem o príncipe querem ser desaprovados, mas sim serem respeitados. Os reis são como o oceano e sua impetuosidade é detida frequentemente, algumas vezes pelas ervas, outras vezes pelos canais" (Montesquieu, 1991, p. 322). A imagem descrita por Montesquieu nos mostra seu entendimento da monarquia e suas relações com os parlamentos. A autoridade do rei e seu conselho nas deliberações das decisões encontram simples obstáculos ou "ervas" ou "canais" que fazem com que estas imposições sejam colocadas em exame e averiguadas. No domínio do poder real isso significa que, alguma vez, o rei é constrangido a justificar e a defender sua política no domínio público e as decisões não permanecem somente entre ele e seu conselho. Montesquieu considera os parlamentos uma forma de oposição real mesmo sendo subordinado era indispensável ao bom funcionamento do regime monárquico.

Interpretar esse período nas diversas configurações que os instituíram, será significativo em dois aspectos. O primeiro refere-se à instituição do Parlamento de Paris que ao poucos foi se distanciando, em certo sentido, do sentido desse prolongamento do "Conselho do Rei" e passaram a elaborar leis que lhe permitiam que suas pretensões tivessem concretizações num duplo direito: o de "registro" de diversas coisas e o de "censura" que era o meio pelo qual os magistrados manifestavam sua oposição à política do rei e ao seu conselho. Os demais parlamentos foram instituídos seguindo o mesmo modelo. $\mathrm{O}$ segundo trata do momento em que se encontrava em declínio o pensamento jurídico na França no inicio do século XVIII por causa da querela existente entre a monarquia francesa do final do século XVII que procurava moldar a política de governo a partir da ênfase do modelo do direito civil romano como forma da presença do Estado nos parlamentos (Kingston, 1996). Como consequência deste modelo político notava-se uma imposição desse modelo com a necessidade das transformações que deveriam corresponder melhor às atribuições do parlamento. A crítica ao modelo romano e universal significava que o rei não estava levando em consideração as características regionais. 
Os parlamentos possuíam funções múltiplas no quadro institucional do Antigo Regime e foram criados como prolongamento do conselho do rei e organizados de acordo com o quadro institucional do Parlamento de Paris. A autoridade dos Parlamentos provinha do seu lugar no sistema real de "justiça delegada" que é exercida em nome do rei, possuíam uma autoridade regional e se colocavam como uma "corte soberana". Essas características institucionais proporcionavam aos magistrados serem de fato representantes da justiça real e do poder político e civil. Isso implicava em aceitar oficialmente as leis e os decretos que emanavam do conselho do rei de maneira a aplicar na sua jurisdição. Evidentemente que o direito de aceitar também propiciava o direito de recusar e como "corte soberana" reconheciam que o poder de recusar era necessário, e para isso eles se dirigiam ao rei através de uma nota oficial de censura apresentando sua objeção à nova lei. Luis XIV procurando limitar a autonomia dos Parlamentos Regionais, respondia a estas censuras, deliberando cartas de ordem ao parlamento convocando uma sessão para assegurar que sua vontade fosse executada, e em casos extremos o rei poderia exilar por completo os parlamentos. Estas cartas eram endereçadas pelo rei as "cortes soberanas" que registravam uma ordem, um edito para serem cumpridas sem contestação.

A ideia de parlamento no pensamento de Montesquieu reflete seu momento presente durante o período em que exerceu sua função de magistrado por doze anos no Parlamento de Bordeaux, e esse cotidiano revela de modo metafórico um prisma de contrastes no Antigo Regime que suas obras nos apresentam como críticas, análises e pensamentos. As Cartas Persas, publicada em 1721, é uma obra epistolar filosófica literária de Montesquieu na qual a leitura do cotidiano de algumas cartas nos esclarecerá sobre o tema.

A ênfase à vida e a obra de Montesquieu é significativa para o entendimento do nosso estudo, destacando alguns aspectos para esclarecer a sua formação, dentre eles, o fato de que ele foi preparado desde a infância para herdar o cargo de "Président à mortier" no Parlamento de Bordeaux de seu tio Jean Baptiste de Secondat. Ele irá exercer sua função de magistrado durante um curto período de 1714 a 1726, e por estar quase sempre ausente gozando do direito de dispensa prévia, pois viajava frequentemente para Paris onde frequentava os teatros, Le Monde, a Corte, os salões e as academias. Refletiu a necessidade de vender seu cargo por não mais se sentir com 
vontade de exercer seu cargo de magistrado e logo a seguir irá fazer uma viagem de três anos pela Europa, "Le Grand Tour".

Durante o período em que Montesquieu ocupou o cargo de "Président à mortier" no Parlamento de Bordeaux percebeu os conflitos existentes entre o conselho do rei e os interesses dos magistrados pertencentes aos parlamentos regionais. As origens desses conflitos são provenientes da não adaptação do modelo do direito civil romano e das transformações que o momento exigia bem como considerar a importância que os aspectos regionais desses parlamentos deviam ter com relação a sua jurisdição. Esses parlamentos se reconhecem como investidos de certa autonomia, mas como "cortes soberanas" num sistema de justiça delegada eram considerados como representantes da justiça real. Montesquieu escreverá a respeito desta importância do contexto político e das decisões que os magistrados exerciam nos parlamentos regionais. Estas transformações eram necessárias para modernização da monarquia. No seu entender o "conselho do rei" não se reduz simplesmente a vontade do rei, mas ao contrário, nele encontramos o Parlamento e as leis que se atribui parte da vontade dele. Montesquieu analisa o contraste entre os magistrados que aplicam as leis e, ao mesmo tempo, estarem contra os abusos do poder real emitindo censuras, notas oficiais fazendo valer o direito de protestar.

A leitura e a análise de algumas cartas do romance epistolar Cartas Persas que menciona alguma critica ao parlamento e a outros temas correlatos nos possibilitará examinar com mais aprofundamento o seu pensamento filosófico e o momento presente.

Na Carta de número 92 onde Usbek escreve a Rédi conta o último acontecimento, que o rei Luis XIV havia falecido. Esta carta relata uma atualidade imediata e ela anuncia a morte do rei três dias mais tarde. "O monarca que reinou por tão longo tempo já não está mais entre nós [...]. O finado rei tinha assinado um testamento que limitava a autoridade do regente" (Montesquieu, 1991, p. 153-154). Luis XIV havia instituído um conselho de regente de quatorze pessoas que decidiria a respeito da maioria dos sufrágios e assinou um testamento anteriormente que dizia respeito ao limite da autoridade do regente. Montesquieu analisando o momento deste acontecimento escreve a respeito das circunstancias destes fatos e seus efeitos. O regente demanda ao Parlamento de Paris para anular o testamento o que foi feito. Os efeitos desses desdobramentos desta anulação que só foi possível em razão ao direito de 
protestar do Regente, que restabelece as cortes de justiça o seu papel no cenário da monarquia que o rei havia retirado (Idem, 2010, p. 244-245).

A anulação do testamento assinala a circunstancia: "Este hábil príncipe foi ao Parlamento" (Idem, Ibidem). Nesta Carta, a narração exprime o instante da percepção analítica de Montesquieu e com ironia ressalta o contraste entre a morte do rei e a habilidade política do regente para circunscrever o presente e mostrar que o declínio do parlamento se encontra nas nuanças das coisas humanas. Numa imagem representativa deste quadro lemos: "Os parlamentos parecem-se com essas ruínas que calcamos os pés, mas que sempre recordam a ideia de algum templo afamado pela antiga religião dos povos. Praticamente a única atribuição que lhes resta é a de dispensar a justiça, e sua autoridade se enfraquece a cada dia, a menos que alguma conjuntura imprevista lhes venha restituir força e vida. Essas grandes corporações cumpriram o destino das coisas humanas: cederam ao tempo, que tudo destrói, à corrupção dos costumes, que tudo debilitou, à autoridade suprema, que tudo derrubou" (MONTESQUIEU, 1991, p. 154). Como decifrar este jogo interpretativo de contrastes estético, retórico e político num tempo indefinido de decadência? A analogia caracteriza a "ruína" e o parlamento que revelam os vestígios de uma autoridade enfraquecida de suas funções. A leitura dessas imagens gráficas plenas de "ideias" não traduzem de maneira clara este momento mas somente uma reflexão com o "templo" antigo e célebre que prezava seu culto. A comparação é uma das maneiras do pensar filosófico de Montesquieu que expressa sua escrita literária para dizer o declínio do parlamento na Carta de Usbek a Rhédi. A análise do declínio é feita para mostrar os efeitos de alguns vestígios que permanecem ainda, "dispensar a justiça" e "autoridade enfraquecida" em que não se pode mais atribuir seu papel importante na monarquia. O acaso pode deslumbrar algum renascimento dessa instituição e como coisas humanas ela se compara ao fim necessário, pois "cumpriram o destino das coisas humanas". O pensamento de Montesquieu nos revela a intensidade e a tensão de ideias que exprimem o presente deste diálogo epistolar em que os acontecimentos reproduzem naturalmente seu percurso de declínio pelo "tempo, costume e autoridade suprema" que verbaliza suas ações que "destrói, debilitou e derrubou”. A escrita de Montesquieu retrata o quadro representativo da época do Antigo Regime com ironia, crítica para nos mostrar as nuanças políticas desse jogo de poder. 
O regente "hábil" reconquista sua "autoridade legitima" e Montesquieu descreve sua visibilidade no reino que buscou ofuscar do Rei Sol nestes termos: “[...] começou seu governo parecendo respeitar essa imagem de autoridade pública; e, como se pensasse em erguer da terra o templo e o ídolo, quis que os Parlamentos fossem considerados como o sustentáculo da monarquia e o fundamento de toda autoridade legítima" (Idem, 1991, 154). Montesquieu descreve outro quadro nesta Carta num estilo retórico analisa as vicissitudes políticas e coloca em cena os Parlamentos nesse cenário. A visibilidade do regente desvia-se para outro espaço e lugar não se encontrando mais na corte ou no Palais de Versailles de Luis XIV para situar-se nos Parlamentos. Desejando agradar e estar presente, governa e legitima seu poder e autoridade numa “imagem pública” a ser reconhecida por todos os súditos. O regente e os Parlamentos ocupam sua representatividade nessa outra forma de dizer à monarquia que traz o visível numa analogia que Montesquieu traduz "erguer da terra o templo e o ídolo". Essa imagem fantástica e teatral da política desta época monárquica francesa de criar cenários imaginários de uma governabilidade aparente e limitada no tempo enquanto o herdeiro não estiver no trono, não deixa de ser para Montesquieu uma curiosa ironia a refletir. O regente em cena quis "respeitar essa imagem da liberdade pública" e fazer prevalecer os Parlamentos que são os depositários das leis fundamentais do reino e os conselheiros do soberano.

Nas Cartas Persas, Montesquieu escreve cartas entre os personagens persas que contam como se sentem, pensam e observam o mundo europeu. "Mas, escrevendo em forma de cartas, em que os atores não são selecionados e que os assuntos tratados não dependem de nenhum propósito ou plano previamente elaborado" (Idem, 1991, p. 263264) o leitor depara-se com variedade de temas. Um mundo presente se deslumbra visível e com nuanças para caracterizar um tempo da galanteria, do jogo, do reino do prazer, do favor e do dinheiro, da decadência da nobreza, dos parlamentos e do mundo da Regência que Montesquieu nos retrata nessa obra. As Cartas Persas é um jogo descontinuo de ideias, imagens e reflexões, mas um jogo incerto e verossímil que Montesquieu conduz seu leitor. Nosso estudo da ideia de parlamento nessa obra procurou analisar o pensamento de Montesquieu dessas perspectivas. 


\section{Referencias bibliográficas}

Montesquieu, Cartas Persas, tradução Renato Janine Ribeiro, São Paulo, Editora Paulicéia, 1991.

, Lettres Persanes, Éditions de Paul Vernière, mise à jour par Catherine Volphilac-Auger, Paris, Classiques Garnier, 2010.

, Pensées et Le Spicilège, Édition établie par Louis Desgraves, Édition

Robert Laffont, 1991.

Kingston, R., Montesquieu and Parliament of Bordeaux, Genève, Droz Librairie, 1996. 